\title{
Puccinia nakanishikii, nova ocorrência de ferrugem em capim- limão (Cymbopogon citratus) no Brasil
}

\author{
Maruzanete P. Melo', João S.P. Araújo ${ }^{1}$, Anibal A. Carvalho Junior ${ }^{2}$, Guilherme O. Tostes ${ }^{1}$ \& \\ Maysa S. Arêas ${ }^{1}$
}

'Departamento de Fitotecnia, Universidade Federal Rural do Rio de Janeiro, 23890-000, Seropédica, RJ, Brasil; ${ }^{2}$ Instituto de Pesquisas, Jardim Botânico do Rio de Janeiro, 22460-030, Rio de Janeiro, RJ, Brasil

Autor para correspondência: Anibal A. Carvalho Junior, e-mail: anibal@jbrj.gov.br

\begin{abstract}
RESUMO
Em amostra de ferrugem sobre Cymbopogon citratus (capim-limão) coletada nos jardins medicinais no Município de Seropédica, Estado do Rio de Janeiro, foi identificado o fungo Puccinia nakanishikii (Uredinales). Esta é a primeira ocorrência desta espécie no Brasil. Diferencia-se de Puccinia cymbopogonis, outra espécie do gênero anteriormente registrada no país sobre o mesmo hospedeiro, principalmente devido à ornamentação equinulada dos urediniósporos e à presença de paráfises capitadas nos uredinióssoros. Uma amostra de referência foi depositada no Herbário do Instituto de Pesquisas Jardim Botânico do Rio de Janeiro (RB).
\end{abstract}

Palavras-chave: Uredinales, Poaceae, etiologia, doença de planta.

\section{ABSTRACT \\ Puccinia nakanishikii, a new report of rust on lemongrass in Brazil}

A sample of a rust fungus on Cymbopogon citratus (lemongrass) was collected in medicinal gardens in the municipality of Seropédica, State of Rio de Janeiro. The fungus was identified as Puccinia nakanishikii (Uredinales). This is the first report of this species in Brazil. It differs from Puccinia cympopogonis, another species belonging to the same genus and also recorded on the same host in Brazil, mainly by the presence of equinulate urediniospores, and capitate paraphyses within its urediniospores. A voucher was deposited in the Herbarium RB, at the Jardim Botânico do Rio de Janeiro.

Keywords: Uredinales, Poaceae, etiology, plant disease.

Cymbopogon citratus (DC) Stamp (capim-limão) é uma planta semi-perene da família Poaceae, muito conhecida por suas propriedades medicinais. Em jardins medicinais da Universidade Federal Rural do Rio de Janeiro e de propriedades rurais próximas, foram coletadas amostras de plantas apresentando sintomas de ferrugem. Uma amostra foi encaminhada para o Laboratório de Micologia do Instituto de Pesquisas Jardim Botânico do Rio de Janeiro, onde foi examinada sob estereomicroscopio da marca Leika (modelo S6E). Lâminas com estruturas do fungo foram preparadas em lactofenol e hidrato de cloral para observação das estruturas sobre um microscópio Zeiss, modelo Axioskop 40, com câmera digital AxioCam MRc. O fungo apresentava as seguintes estruturas e características morfológicas. Espermogônios e écios não vistos; Uredinióssoros na face abaxial, em manchas cloróticas a necróticas, alongados (Figura 1A), marrom canela-claros a marrom canela-escuros, paráfises capitadas ou clavadacapitadas, paredes finas abaixo e engrossadas acima, 6-7 $\mu \mathrm{m}$ espessas no ápice (Figura 1B), de amarelo-pálidas a amareloouro, urediniósporos abundantes, obovóides, 27-34 x 21-25 $\mu \mathrm{m}$, marrom canela-escuros abaixo e marrom acastanhados acima, equinulados, poros germinativos 4 a 5 equatoriais (Figura 1C); teliósporos tardios, produzidos a partir dos urediniossoros, em sua maioria elipsóides, medindo 31-38 x 21-27 $\mu \mathrm{m}$, bicelulares, marrom-castanhos, lisos, paredes engrossadas até $5 \mu \mathrm{m}$ no ápice, pedicelos marrons e de paredes finas (Figura 1D). Esses marcadores morfológicos são característicos da espécie Puccinia nakanishikii Dietel (Uredinales). Trata-se de espécie de ampla distribuição, com registros na África, Índia, Ceilão, Nova Guiné, Filipinas, China e Japão (Cummins, 1971), e Estados Unidos - Havaí (Gardner, 1985) e Califórnia (Koike, 1999). Recentemente, Puccinia cymbopogonis Massee, outra ferrugem sobre $C$. citratus, foi registrada nos estados do Paraná (Vida et al, 2006) e no Estado de São Paulo (Russomano et al., 2008). As principais características distintivas entre as espécies são as seguintes. P. nakanishikii possui urediniossoros com paráfises evidentes, capitadas ou clavado-capitadas, enquanto em $P$. cymbopogonis podem ser facilmente confundidas com os pedicelos; os urediniósporos da primeira espécie são ligeiramente mais longos e mais espessos no ápice e possuem ornamentação equinulada enquanto a segunda tem ornamentação finamente verrugosa; os teliósporos de $P$. nakanishikii não possuem umbo evidente na célula distal, enquanto $P$. cymbopogonis é umbonado e com parede mais espessa distalmente. A ferrugem foi observada em todas as estações do ano, sendo a severidade da doença mais 


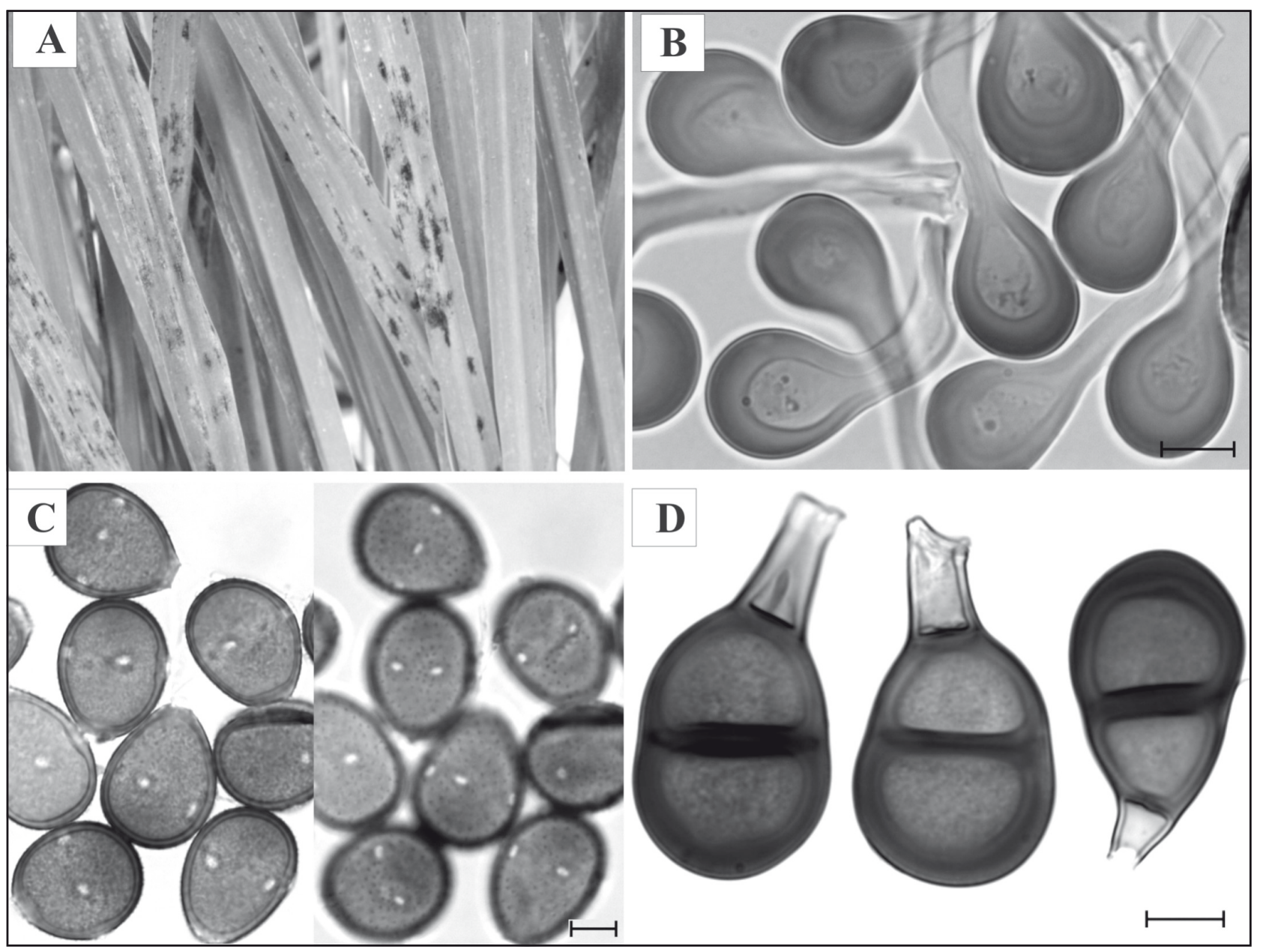

FIGURA 1 - Puccinia nakanishikii. A. Sintomas da ferrugem em folhas de capim-limão; B. Paráfises capitadas; C. Urediniósporos - à esquerda - em vista mediana - mostrando forma, espessura das paredes e poros germinativos - à direita - em vista superficial mostrando ornamentação equinulada; D. Teliósporos. Escala de barras $=10 \mu \mathrm{m}$.

expressiva no período de inverno. Este é o primeiro relato de P. nakanishikii no Brasil. Uma amostra do material foi depositada no Herbário do Instituto de Pesquisas Jardim Botânico do Rio de Janeiro, sob o número RB 452833.

\section{AGRADECIMENTOS}

Os autores agradecem à Fundação Carlos Chagas Filho de Amparo à Pesquisa do Estado do Rio de Janeiro - FAPERJ e ao Conselho Nacional de Desenvolvimento Científico e Tecnológico - CNPq pelo apoio financeiro recebido. Os autores Maruzanete Pereira de Melo e Guilherme de Oliveira Tostes receberam bolsa de iniciação científica da FAPERJ e do CNPq respectivamente.

\section{REFERÊNCIAS BIBLIOGRÁFICAS}

Cummins GB (1971) The rust fungi of cereals, grasses and bamboos. New York NY. Springer Verlag.

Gardner DE (1985) Lemongrass rust caused by Puccinia nakanishikii in Hawai. Plant Disease 12:1100.

Koike ST (1999) Rust disease on lemongrass in California. Plant Disease 83:304.

Russomano OMR, Krupa PC, Coutinho LN, Silva MP, Carvalho AM (2008) Ocorrência de ferrugem em plantas de capimlimão (Cymbopogon citratus) no Estado de São Paulo. Summa Phytopathologica 34:81. Resumo

Vida JB, Carvalho Jr. AA, Verzignassi JR (2006). Primeira ocorrência de ferrugem causada por Puccinia cymbopogonis no Brasil. Summa Phytopatologica 32:89-91. 